\title{
Application of Absorption and Scattering Properties Obtained through Image Pre-Classification Method Using a Laser Backscattering Imaging System to Detect Kiwifruit Chilling Injury
}

\author{
Zhuo Yang ${ }^{1,2,3}$, Mo Li ${ }^{1, *}$, Andrew R. East ${ }^{1}$ and Manuela Zude-Sasse ${ }^{3, *(D)}$ \\ 1 MAF Digital Lab, Massey University, 4472 Palmerston North, New Zealand; Z.Yang1@massey.ac.nz (Z.Y.); \\ A.R.East@massey.ac.nz (A.R.E.) \\ 2 School of Food and Advanced Technology, Massey University, 4410 Palmerston North, New Zealand \\ 3 Leibniz Institute for Agricultural Engineering and Bioeconomy (ATB), 14469 Potsdam, Germany \\ * Correspondence: M.Li2@massey.ac.nz (M.L.); mzude@atb-potsdam.de (M.Z.-S.)
}

Citation: Yang, Z.; Li, M.; East, A.R.; Zude-Sasse, M. Application of Absorption and Scattering Properties Obtained through Image Pre-Classification Method Using a Laser Backscattering Imaging System to Detect Kiwifruit Chilling Injury. Foods 2021, 10, 1446. https://doi.org/ 10.3390 /foods 10071446

Academic Editors

Margarita Ruiz-Altisent and

Belén Diezma

Received: 21 May 2021

Accepted: 18 June 2021

Published: 22 June 2021

Publisher's Note: MDPI stays neutral with regard to jurisdictional claims in published maps and institutional affiliations.

Copyright: (c) 2021 by the authors. Licensee MDPI, Basel, Switzerland. This article is an open access article distributed under the terms and conditions of the Creative Commons Attribution (CC BY) license (https:// creativecommons.org/licenses/by/ $4.0 /)$

\begin{abstract}
Kiwifruit chilling injury (CI) damage occurs after long-term exposure to low temperature. A non-destructive approach to detect $\mathrm{CI}$ injury was tested in the present study, using a laser backscattering image (LBI) technique calibrated with 56 liquid phantoms for providing absorption coefficient $\left(\mu_{\mathrm{a}}\right)$ and reduced scattering coefficient $\left(\mu_{\mathrm{s}}{ }^{\prime}\right)$. Calibration of LBI resulted in a true-positive (TP) classification of $91.5 \%$ and $65.6 \%$ of predicted $\mu_{\mathrm{s}}{ }^{\prime}$ and $\mu_{\mathrm{a}}$, respectively. The optical properties of 'SunGold ${ }^{\mathrm{TM}}$ 'and 'Hayward' kiwifruit were analysed at $520 \mathrm{~nm}$ with a two-step protocol capturing pre-classification according to the LBI parameters used in the calibration and estimation with the Farrell equation. Severely injured kiwifruit showed white corky tissue and water soaking, reduced soluble solids content and firmness measured destructively. Non-destructive classification results for

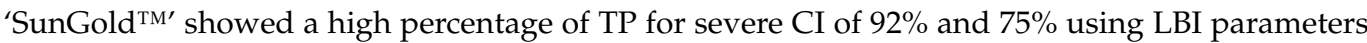
directly and predicted $\mu_{\mathrm{a}}$ and $\mu_{\mathrm{s}}{ }^{\prime}$ after pre-classification, respectively. The classification accuracy for severe CI 'Hayward' kiwifruit with LBI parameter was low (58\%) and with $\mu_{\mathrm{a}}$ and $\mu_{\mathrm{s}}$ ' decreased further $(35 \%)$, which was assumed to be due to interference caused by the long trichomes on the fruit surface.
\end{abstract}

Keywords: non-destructive detection; diffusion theory; spatially-resolved; optical phantom

\section{Introduction}

Kiwifruit chilling injury $(\mathrm{CI})$ is a physiological response that causes cell damage during long term storage at low temperature [1]. Symptoms of kiwifruit CI are complex and can be observed on the exocarp and mesocarp tissue. Initial symptoms are only visible when cutting the fruit. Early-stage symptoms of CI can be observed as white spots in the mesocarp tissue at the stylar end, which develop to severe symptoms of granulation and water soaking [2]. The incidence and severity of kiwifruit CI are affected by harvest maturity, particularly early harvest fruit are more susceptible to CI [3]. Rapid cooling [4], lower temperature during long-term storage [5] and exposure to ethylene [6] can also exacerbate CI incidence. CI can affect fruit quality, external appearance, respiration rate, and ethylene production [7]. Failure to detect kiwifruit CI may, therefore, result in a significant fruit loss during storage and marketing [8].

At present, kiwifruit CI is assessed visually by cutting a subsample of fruit from a grower line batch before exporting, assuming that the sample is representative of the entire population. A reliable non-destructive technique is desired for kiwifruit CI detection enabling inline grading of entire batches of fruit before marketing. Optical measuring principles have been demonstrated to non-destructively detect fruit internal disorders previously. Magnetic resonance imaging (MRI) techniques were applied to rapidly detection 
moth infestation [9], bruising [10], and mealiness [11] of apple. Soft X-ray imaging was applied to classify bruise [12] and watercore [13]. Thermal imaging has been used to detect apple bruising [14]. However, MRI has been confirmed for analysing the structure of fruit tissue including water soaking, but is still very expensive and the analysis is slow, which makes the technique less suitable for sorting fruit. Soft X-ray imaging requires advanced segmentation to distinguish new bruises within apple tissue, which might be challenging for granulation detection for intact kiwifruit. However, this needs to be further studied. Although IR has advantages such as a large measurement area and suitability for moving fruit on the sorting line, IR typically requires temperature adjustment while recording the thermal activities in the sample of interest and the thermal camera can be costly. This measuring scenario may create challenges in industrial applications. Additionally, IR seems to be more suitable at detecting more severe tissue damage caused by mechanical damage (e.g., bruised tissue) which would alter thermal emissivity of the fruit. For chilling injury, especially when symptoms are mild to moderate (i.e., granulation of tissue without water soaking appearance) the application may not be feasible.

Near infrared (NIR) spectroscopy has been applied earlier to detect CI in fruit and vegetables [15]. Wang et al. segregated sound kiwifruit and kiwifruit with CI using NIR spectral information and reported a stronger separation at the stylar end compared to the analysis in the equatorial region [16]. Kemsley et al. investigated NIR diffuse optical tomography at $689 \mathrm{~nm}$ and reported internal defect detection in potatoes [17]. Hyperspectral image analysis has been widely investigated for evaluating horticultural products [18]. Since CI involves pigment changes for some crops, the capacity of spectral data in CI detection appears reasonable. In Wang et al.'s study [16], kiwifruit were segregated in severe CI cases when discolouration had already occurred. Cen et al. applied selected wavelengths and image features to detect CI symptoms of brown spots in cucumber and achieved 100\% classification accuracy for a two-class classification [19]. Hyperspectral imaging at selected wavelengths was used for CI detection in apples, obtaining $98.4 \%$ overall classification accuracy [20]. So far, no early detection of CI in kiwifruit has been reported.

Limitations of 'point' NIR spectroscopy and hyperspectral imaging technique include the high cost for hardware and complex data analysis. Wavelength selection and binning techniques have been explored to reduce the data processing time and cost of the sensor hardware since the selection of relevant wavelengths enables a multi-spectral sensor setup with less expensive hardware. However, a drawback for obtaining fruit information from spectroscopy is related to the varying cell wall structure of the sample, which affects the spectral intensities measured due to its effect on the scattering events in the tissue. The apparent spectral-optical information represents the sum signal of absorption and scattering. Li et al. investigated the postharvest quality of kiwifruit using the NIR technique to predict kiwifruit storability and reported poor prediction performance of kiwifruit firmness [21]. ElMasry et al. predicted Red Delicious apple firmness using hyperspectral imaging and obtained high root mean square error $(8.26 \mathrm{~N}$ and $9.40 \mathrm{~N}$ for training and validation, respectively) despite a $90 \%$ classification accuracy [20]. Walsh et al. explained in their review that errors could occur when using spectral reflectance data to predict fruit quality, because the sum signal changes with both chemical composition and physical properties [15]. CI at the early stage represents the appearance of granular tissue that may mainly affect the scattering properties of the fruit. Therefore, a non-destructive technique with the potential for measuring mainly the scattering property of the fruit tissue is desired.

A laser backscattering image (LBI) system is a multi-spectral system based on preselected wavelengths. The sum signal of absorption and scattering is recorded via an image of diffusely reflected light from the laser incident point till attenuation of light in the tissue. This method has been identified as providing information that distinguishes absorption and reduced scattering properties using the radial light attenuation profile followed by appropriate data analysis [22]. The decoupled absorption coefficient $\left(\mu_{\mathrm{a}}\right)$ and reduced scattering coefficient $\left(\mu_{\mathrm{s}}{ }^{\prime}\right)$, which are related to chemical composition and cell wall structure, may be correlated with internal disorder symptoms of water soaking, discolouration and 
corky tissue. In previous research, fruit's optical properties were predicted via a curve fitting process in the diffusion model developed by Farrell et al. [22]. In this case, LBI may be more useful as it is potentially more sensitive to detecting changes in the scattering of photons as a result of tissue granulation. Additionally, the cost of LBI system components (laser diode and CCD camera) is reasonable compared to other non-destructive systems. LBI system is easy to be implemented on existing fruit sorting/grading line.

LBI profiles were applied to identify CI in banana and reported LBI parameters were correlated with fruit quality parameters that could potentially indicate pigment changes due to CI [23]. Lu and Peng used a multi-spectral scattering profile with Lorentzian distribution to predict peach firmness [24]. A broader scattering profile of soft fruit than firm fruit was observed, and Lorentzian parameters were linearly related to fruit firmness. Van Beers et al. applied relative reflection profile data to predict apple maturity and observed good prediction performance of at-harvest maturity and starch level, but poor performance for SSC and firmness prediction [25]. Peng and Lu approached an improvement of firmness analysis by adding shape correction [26]. However, the decoupling of $\mu_{\mathrm{a}}$ and $\mu_{\mathrm{s}}$ ' remains a major challenge for LBI when applied to predict fruit quality. Baranyai and Zude investigated the apple scattering coefficient from LBI image via Monte Carlo simulation and reported that LBI profiles changed with induced bruising symptoms [27]. However, it was also reported that simulation of high scattering - low absorbing and low scatteringhigh absorbing samples were hardly distinguishable. Zude-Sasse et al. validated optical properties of pear using the destructive photon density wave (PDW) method and found that measuring uncertainty could be introduced during the curve fitting process without limiting the range of either $\mu_{\mathrm{a}}$ or $\mu_{\mathrm{s}}{ }^{\prime}$ according to known values of one variable by means of destructive analysis [28]. Therefore, a calibration of the LBI system and the according pre-classification of $\mu_{\mathrm{a}}$ or $\mu_{\mathrm{s}}$ ' ranges before the fitting process could potentially reduce the measuring uncertainty.

This so-called metamodeling was introduced for bridging the gap between the mathematical model and real-world fruit by using the LBI parameter of liquid phantoms to provide a reference matrix for pre-classifying the ranges of optical properties of fruit samples $[18,28]$. Liquid phantoms are turbid media with absorbers at a known concentration and lipids serving as scatterers. The optical properties were estimated and validated by Aernouts et al. and Watté et al. [29,30]. Yang et al. investigated kiwifruit optical properties using solid phantoms and found that the range of $\mu_{\mathrm{a}}\left(\mathrm{cm}^{-1}\right) \in[0,1.2]$ and $\mu_{\mathrm{s}}{ }^{\prime}\left(\mathrm{cm}^{-1}\right) \in[0,15]$ should be resolved at a higher resolution for kiwifruit compared to currently reported metamodels [31].

The objectives of the present study were to (1) develop a pre-classification model for segregating LBI images with $\mu_{\mathrm{a}}$ or $\mu_{\mathrm{s}}$ ' using liquid phantom profiles with enhanced resolution of $\mu_{s}^{\prime}$ and $\mu_{\mathrm{a}}$; and (2) investigate whether optical properties calculated after preclassification could be used to distinguish sound kiwifruit and kiwifruit with CI symptoms.

\section{Materials and Methods}

\subsection{Fruit Materials}

'Hayward' kiwifruit (Actinidia chinensis var. deliciosa, $n=400$ ) were harvested at 8 maturity stages from 6 April-1 June 2020 at weekly intervals. Kiwifruit were harvested from one commercial orchard and stored at $-0.5{ }^{\circ} \mathrm{C}$ for 22 weeks to induce $\mathrm{CI}$ symptoms. LBI data and CI symptoms were measured after storage.

Cool stored 'SunGold ${ }^{\mathrm{TM}}$ ' kiwifruit (A. chinensis var. chinensis, $n=396$ ) were delivered to Massey University on August 14th 2020 from 3 growers after 20 weeks of storage. 'SunGold ${ }^{\mathrm{TM}}$ ' kiwifruit samples were stored at $1{ }^{\circ} \mathrm{C}$ cold room for 30 days and were measured subsequently after warming up to $20^{\circ} \mathrm{C}$ overnight.

\subsection{LBI Image Capture}

The LBI imaging system (Figure 1a) was assembled at Massey University, New Zealand. The system included the light source with a laser diode (FP-D-DIG-520-17- 
C-F250-USB, Laser Components, Germany) emitting at $520 \mathrm{~nm}$ with $6.8 \mathrm{~mW}$ of power output, a charge-coupled device (CCD) camera (MER-131-210U3M NIR, China Daheng Group, China) providing resolution of $1280 \times 1024$ pixels, equipped with F1.4 aperture zoom lens and 10-40 mm focal length (12VG1040 ASIR-SQ, Tamron Co. Ltd., Saitama, Japan), and a desktop computer to control the light source and camera. An electrical moving table was used to adjust the sample position to maintain a distance of $25 \mathrm{~cm}$ between the highest point of the fruit surface and the camera.

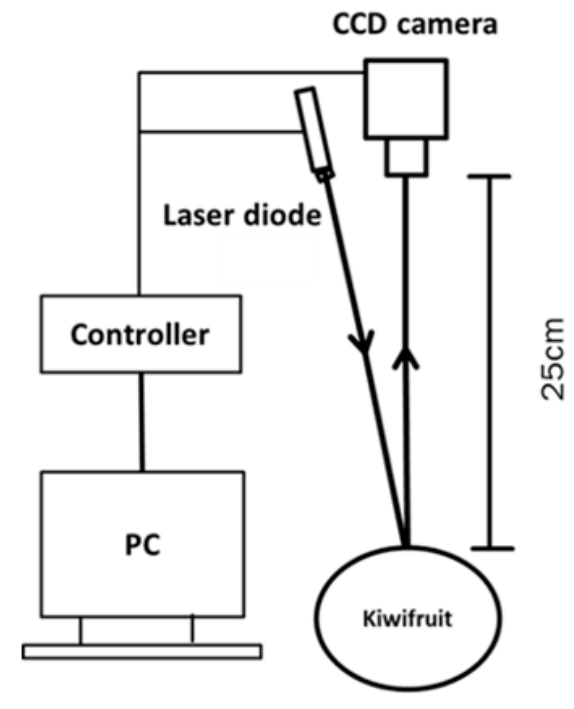

(a)

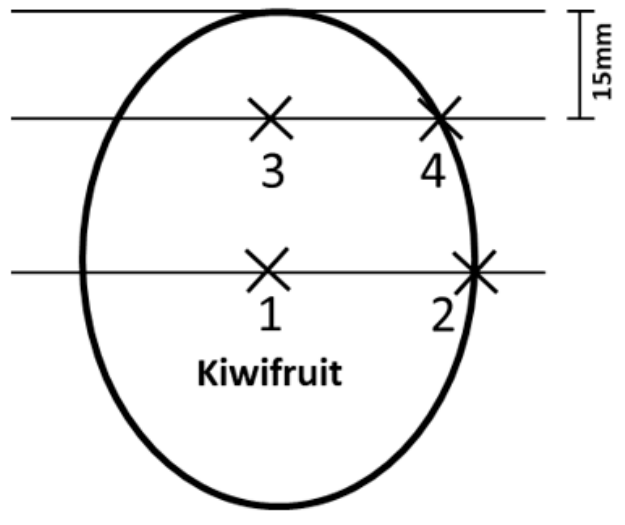

(b)

Figure 1. (a) Laser backscattering imaging system; (b) kiwifruit assessment. Cross-marks of the laser pointer focus (3, 4 in the stylar end region; 1, 2 in the equatorial region), cut line to assess kiwifruit chilling injury.

Non-destructive LBI measurement was conducted at $520 \mathrm{~nm}$, which is the absorption peak of carotenoids. Each kiwifruit was placed longitudinally on the moving table. Kiwifruit LBIs were taken at 4 positions with 2 each (at $90^{\circ}$ apart) on the equatorial and the stylar end region (1.5 $\mathrm{cm}$ from the end) (Figure $1 \mathrm{~b}$ ). The 4 positions corresponded to the focus points of the laser pointer when imaging the samples. A custom written Labview software (National Instruments, Austin, TX, USA) was used to control the system. Each resulting LBI was the average image of 10 images acquired as $0.5 \mathrm{~s}$ per image. Acquisition of the images was done in a dark room and the measuring parts were secured inside a black cage to prevent interfering stray light and avoid exposure to laser light.

\subsection{Kiwifruit Quality Assessment}

Kiwifruit fresh weight was measured using an electronic balance (TW423L, Shimadzu, Japan). Kiwifruit flesh firmness (FF) was determined from penetration tests using a penetrometer (Willowbank Electronics Ltd., Napier, New Zealand) with a standard $7.9 \mathrm{~mm}$ diameter convex Effegi probe at a speed of $8 \mathrm{~mm} \mathrm{~s}^{-1}$ to $8 \mathrm{~mm}$ depth. Before the measurement, $2 \mathrm{~mm}$ of skin slice was removed at two equatorial positions ( $90^{\circ}$ apart). Kiwifruit FF was recorded as the average of the two readings. The SSC (\%) of kiwifruit was measured by a refractometer (PR-32 $\alpha$, Atago, Tokyo, Japan) at $20^{\circ} \mathrm{C}$. Kiwifruit samples were cut into half at the equator and juice extracted by hand from the stylar end half. Kiwifruit longitudinal profile (lp) was calculated using kiwifruit length, minor diameter and major diameter [32].

\subsection{Kiwifruit CI Assessment}

Kiwifruit samples were cut along the marked position at the stylar end (Figure 1b) for manual observation of the CI severity. The CI assessment was carried out at the four 
locations matching the LBI measurement area. The severity score was obtained using a scale provided by Wang et al. and was recorded as $\mathrm{CI}_{\text {se }}$ and $\mathrm{CI}_{\mathrm{eq}}$ for the stylar end and equatorial section of kiwifruit, respectively [16].

\subsection{LBI Profile Analysis}

Raw LBI (Figure 2a) was analysed by R (version 3.6.0, R Foundation for Statistical Computing, Vienna, Austria) running in RStudio (version 1.0.153, RStudio Inc., Boston, MA, USA). An average of 10 LBI were used in further analysis. In the geometric calibration, one pixel represented $0.01015625 \cdot 0.01015625 \mathrm{~cm}^{2}$. The raw image was transformed into a grey-scale matrix using the 'readbitmap' package (version 0.1.5). The backscattering intensity matrix was computed into LBI light attenuation profiles. LBI parameters were extracted as the radius of the saturated area (distance to incident point, DIP), the radius at $75 \%$ of maximum intensity (Q1R), double the radius at $50 \%$ of maximum intensity (full width half maximum, FWHM), the radius at $25 \%$ of maximum intensity (Q3R), and the negative slope (SLP) of the linear regression model [31] built with log-transformed profile data between Q1R and Q3R (Figure 2b).

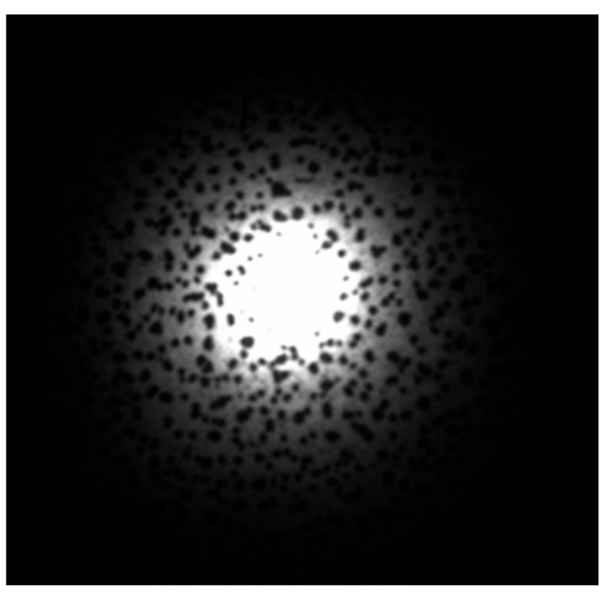

(a)

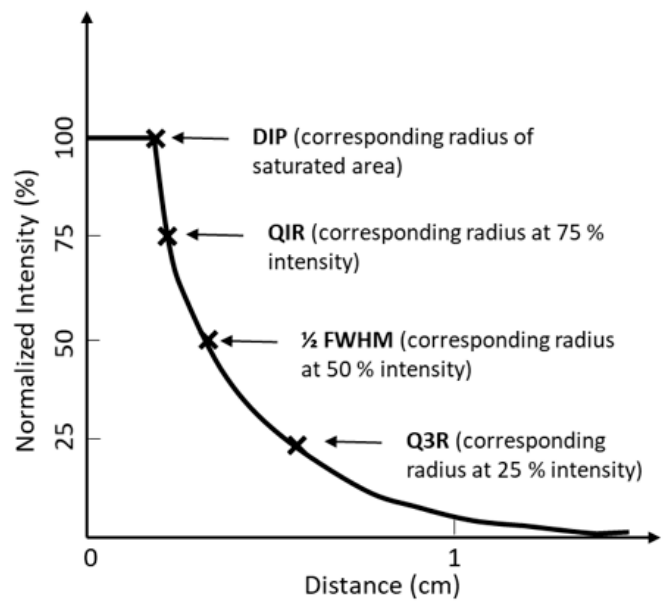

(b)

Figure 2. (a) 'SunGold ${ }^{\mathrm{TM}}$ ' kiwifruit LBI; (b) transformed diffusion profile from laser backscattering image (LBI). LBI parameters were the radius of the saturated area (distance to incident point, DIP), the radius at $75 \%$ of maximum intensity (Q1R), double the radius at 50\% of maximum intensity (full width half maximum, FWHM), the radius at $25 \%$ of maximum intensity (Q3R), and the negative slope (SLP) of the linear regression model built with log-transformed profile data between Q1R and Q3R.

LBI parameters were extracted from images obtained at the stylar end (se)-positions 3 and 4, Figure 1, and equatorial region (eq)-positions 1 and 2, Figure 1, respectively, as well as from all images of the whole fruit (wf)-mean of positions 1-4, Figure 1 . In a three-class classification, LBI and kiwifruit were segregated into Sound (free from CI symptoms), Moderate (CI symptoms of granulation but without water soaking) and Severe (CI symptoms of both granulation and water soaking).

\subsection{Liquid Phantoms and Pre-Classification Model}

A total of 56 liquid phantoms were prepared for pre-classification model calibration. Liquid phantoms were made by Intralipid ${ }^{\circledR} 20 \%$ (batch 80NC095, Fresenius Kabi, Germany) and Naphthol Blue Black (NBB) (Sigma-Aldrich, St. Louis, MO, USA) 5 mM stock solution. The absorbers of liquid phantoms are ink particles, and the scatterers are lipid particles. The designed phantom set had 4 levels of scattering at 3.12\%,5.2\%, 7.28\% and 9.36\% of Intralipid ${ }^{\circledR}$, and 14 levels of absorption between $0-0.65 \%$ of NBB at $0.05 \%$ interval. Phantom solutions were made using $250 \mathrm{~mL}$ volume flasks then transferred into $280 \mathrm{~mL}$ black plastic containers $(41 \times 118 \mathrm{~mm})$ for LBI acquisition. Liquid phantom LBI images were obtained 
immediately after preparation of phantoms by placing the container in the centre of the moving table of LBI system. Liquid phantom LBI images were pre-processed to remove the reflection spot within the diffusion area. LBI diffusion profiles were extracted from the pre-processed picture.

The absorption coefficient of the liquid phantom $\mu_{\mathrm{a}}{ }^{*}$ was measured using a UVvisible recording spectrophotometer (UV-16 A, SHIMADZU, Japan) at different NBB concentrations. Measured $\mu_{\mathrm{a}}{ }^{*}$ was linearly correlated $\left(\mathrm{R}^{2}=0.998\right)$ with NBB concentration maybe due to minor handling errors.

$$
\mu_{\mathrm{a}}^{*}=-0.0816 \mathrm{~A}-0.0624
$$

in which, $\mu_{\mathrm{a}}^{*}$ of the phantom referred to the calculated absorption coefficient of NBB solution according to measured absorbance, A (Equation (1)). This equation was built according to measured data.

A minimum $\mu_{\mathrm{a}}{ }^{*}$ was set as $1 . \mathrm{e}^{-10}$ as $\mu_{\mathrm{a}}{ }^{*} \neq 0$ was a condition in the curve fitting process [22]. The estimated $\mu_{\mathrm{a}}$ range (Equation (2)) was then calculated as

$$
\mu_{\mathrm{an}}{ }^{*} \in\left[\mu_{\mathrm{an}}-\left(\mu_{\mathrm{an}}-\mu_{\mathrm{an}-0.05}\right) / 2, \mu_{\mathrm{an}}+\left(\mu_{\mathrm{an}+0.05}-\mu_{\mathrm{an}}\right) / 2\right]
$$

in which, $\mu_{\mathrm{an}}{ }^{*}$ is $\mu_{\mathrm{a}}{ }^{*}$ with $n \%$ of NBB.

The estimated reduced scattering coefficient of the liquid phantom $\mu_{\mathrm{s}}{ }^{*}$ was measured according to Watté et al. at different Intralipid ${ }^{\circledR} 20 \%$ concentration [30]. A linear regression $\left(R^{2}=0.99\right)$ was found using Intralipid ${ }^{\circledR} 20 \%$ concentration and estimated $\mu_{\mathrm{s}}{ }^{*}$ described by

$$
\mu_{\mathrm{s}}{ }^{*}=-0.003272+2.985451 \cdot \mathrm{C} \cdot 20 \%
$$

in which, $\mu_{\mathrm{s}}{ }^{*}$ represented the estimated reduced scattering coefficient of liquid phantoms and $C$ was Intralipid ${ }^{\circledR}$ concentration. The resulting $\mu_{s}{ }^{\prime *}$ levels are given in Table 1 , providing $\mu_{\mathrm{s}}{ }^{\prime}$ ranges calculated with Equation (2).

Table 1. Averaged $\mu_{\mathrm{s}}{ }^{\prime}\left(\mathrm{cm}^{-1}\right)$ predicted at $\mu_{\mathrm{a}}{ }^{*}=0 ; \mu_{\mathrm{s}}{ }^{\prime}\left(\mathrm{cm}^{-1}\right)$ predicted directly from non-destructive LBI without pre-classification (both open range); $\mu_{\mathrm{s}}{ }^{\prime}\left(\mathrm{cm}^{-1}\right)$ predicted after pre-classification based on LBI parameters.

\begin{tabular}{ccccc}
\hline $\boldsymbol{\mu}_{\mathrm{s}}{ }^{*}$ & Range & $\boldsymbol{\mu}_{\mathrm{s}}{ }^{\prime}\left(\boldsymbol{\mu}_{\mathrm{a}}{ }^{*}=\mathbf{0}\right)$ & $\begin{array}{c}\boldsymbol{\mu}_{\mathrm{s}}{ }^{\prime} \text { (Open } \\
\text { Range) }\end{array}$ & $\begin{array}{c}\boldsymbol{\mu}_{\mathrm{s}}{ }^{\prime} \text { (with Pre- } \\
\text { Classification) }\end{array}$ \\
\hline 1.86 & $0.1-2.5$ & 1.41 & 3.39 & 1.11 \\
3.10 & $2.6-3.6$ & 1.56 & 3.93 & 2.61 \\
4.34 & $3.7-4.8$ & 1.73 & 4.26 & 3.57 \\
5.59 & $4.9-6.5$ & 1.90 & 4.31 & 4.36 \\
\hline
\end{tabular}

Liquid phantom extracted LBI parameters, $\mu_{\mathrm{a}}{ }^{*}$ and $\mu_{\mathrm{s}}{ }^{* *}$ (Equation (3)) were used to calibrate the LBI system and provide the data base for the pre-classification model using flexible discriminant analysis (FDA) with leave-one-out cross-validation to predict the class of $\mu_{\mathrm{a}}$ and $\mu_{\mathrm{s}}{ }^{\prime}$. Kiwifruit LBI parameters were extracted, and attenuation profiles were pre-classified according to the reference classes set by the phantoms. Then, the predicted $\mu_{\mathrm{a}}$ $\left(\mathrm{cm}^{-1}\right)$ and $\mu_{\mathrm{s}}{ }^{\prime}\left(\mathrm{cm}^{-1}\right)$ were subsequently calculated with Farrell's equation considering the ranges from pre-classification. In which $\mu_{\mathrm{a}}{ }^{*}, \mu_{\mathrm{s}}{ }^{\prime *}$ were the known values and $\mu_{\mathrm{a}}$ range (data not shown), $\mu_{s}{ }^{\prime}$ ranges (Table 1 ) were the prediction boundaries for each pre-predicted class in the curve fitting process.

\subsection{Data Analysis}

The quantitative comparison of LBI parameters (DIP, Q1R, FWHM, Q3R, SLP) and kiwifruit optical parameters $\left(\mu_{a}, \mu_{s}^{\prime}\right)$ for sound, moderated and severe samples were subjected to analysis of variance (ANOVA). Tukey's HSD test was applied to test the significance of the variable effect. As the goal is to classify sound and CI kiwifruit, their 
optical properties were analysed via FDA in 'mda' package (version 0.4-10). A confusion matrix was presented to evaluate the performance of the prediction model.

Data were analysed directly and with 10 subsample sets with the same number of severe CI kiwifruit from all categories were chosen by selecting random seeds used to deal with the unbalanced population of sound, moderated and severe CI samples. A confusion matrix was calculated in $\mathrm{R}$ and true positives (TP) given. TP are kiwifruit correctly predicted for each severity.

Two-class segregation was also investigated. Fruit from sound and moderate groups were pooled together and a model was developed to segregate them from the severe group. Because of the large number of fruit in the sound group, data balancing was carried out by assigning the same number of severe to sound and moderate kiwifruit through subsampling, whilst keeping the same ratio of sound and moderate fruit ('SunGold ${ }^{\mathrm{TM}}$ ' $=5: 1$, 'Hayward' = 4:5) in the balanced population. $F_{1}$ score was selected, as a reliable indicator for unbalanced data sets, to predict kiwifruit with severe $\mathrm{CI}$, when comparing the results from the entire population in the two-class segregation. $\mathrm{F}_{1}$ was calculated with performance metrics: precision (P) and recall (R) (Equations (4)-(6)).

$$
\begin{aligned}
& \mathrm{P}=\frac{\mathrm{TP}}{\mathrm{TP}+\mathrm{FP}} \\
& \mathrm{R}=\frac{\mathrm{TP}}{\mathrm{TP}+\mathrm{FN}} \\
& \mathrm{F}_{1}=2 \cdot \frac{\mathrm{P} \cdot \mathrm{R}}{\mathrm{P}+\mathrm{R}}
\end{aligned}
$$

in which, TP were kiwifruit correctly predicted with severe CI, FP were kiwifruit mistakenly predicted with severe CI, TN were kiwifruit correctly predicted as sound or moderate CI and FN were kiwifruit mistakenly predicted as sound or moderate CI.

\section{Results and Discussion}

\subsection{Pre-Classification Model}

LBI diffusion profiles of liquid phantoms were extracted considering varying levels of absorption and scattering. Parameters of LBI profile were extracted (Figure 3), showing that values of DIP, Q1R, FWHM and Q3R decreased at high measured $\mu_{\mathrm{a}}{ }^{*}$, but also at high scattering level. This same result was previously reported for banana, showing that FWHM measured at $660 \mathrm{~nm}$ appeared lower at early green ripening stages with enhanced chlorophyll content compared to yellow ripe fruit with decreased chlorophyll content. The latter resulting in reduced $\mu_{\mathrm{a}}$ at $660 \mathrm{~nm}$ [23]. The difference in LBI parameters among different scattering levels was somewhat stable at all measured $\mu_{\mathrm{a}}{ }^{*}$ levels as illustrated by the clear separation in most cases, while the parameters decreased quickly when $\mu_{\mathrm{a}}{ }^{*}$ changed from 0 to $0.19 \mathrm{~cm}^{-1}$.

In the present study, measured LBI profiles of phantoms with different $\mu_{\mathrm{s}}{ }^{*}$ values appeared separated, suggesting that classification according to the range (Equation (3)) was possible (Figure $4 \mathrm{a}, \mathrm{d}, \mathrm{g}, \mathrm{j}$ ). However, the difference among phantoms with varying $\mu_{\mathrm{s}}{ }^{*}$ became less obvious with increasing absorption levels. In an earlier study, the LBI profiles and its $\mu_{\mathrm{a}}$ and $\mu_{\mathrm{s}}$ ' of 'Conference' pear showed the same trend with increasing $\mu_{\mathrm{a}}$ and decreasing $\mu_{\mathrm{s}}$ ' [33]. Simulation of the profiles was done according to Farrell equation with open ranges, without setting the ranges according to the calibration, but with known $\mu_{\mathrm{a}}{ }^{*}$. Surprisingly, the knowledge on $\mu_{\mathrm{a}}{ }^{*}$ resulted in no clear separation according to the optical properties (Figure $4 \mathrm{~b}, \mathrm{e}, \mathrm{h}, \mathrm{k}$ ). However, when simulating the profiles with known $\mu_{\mathrm{a}}{ }^{*}$ values and pre-classification ranges of $\mu_{\mathrm{s}}{ }^{\prime}$ according to the calibration with liquid phantoms resulted in clear separation of the simulated profiles (Figure $4 \mathrm{c}, \mathrm{f}, \mathrm{i}, \mathrm{l}$ ). 

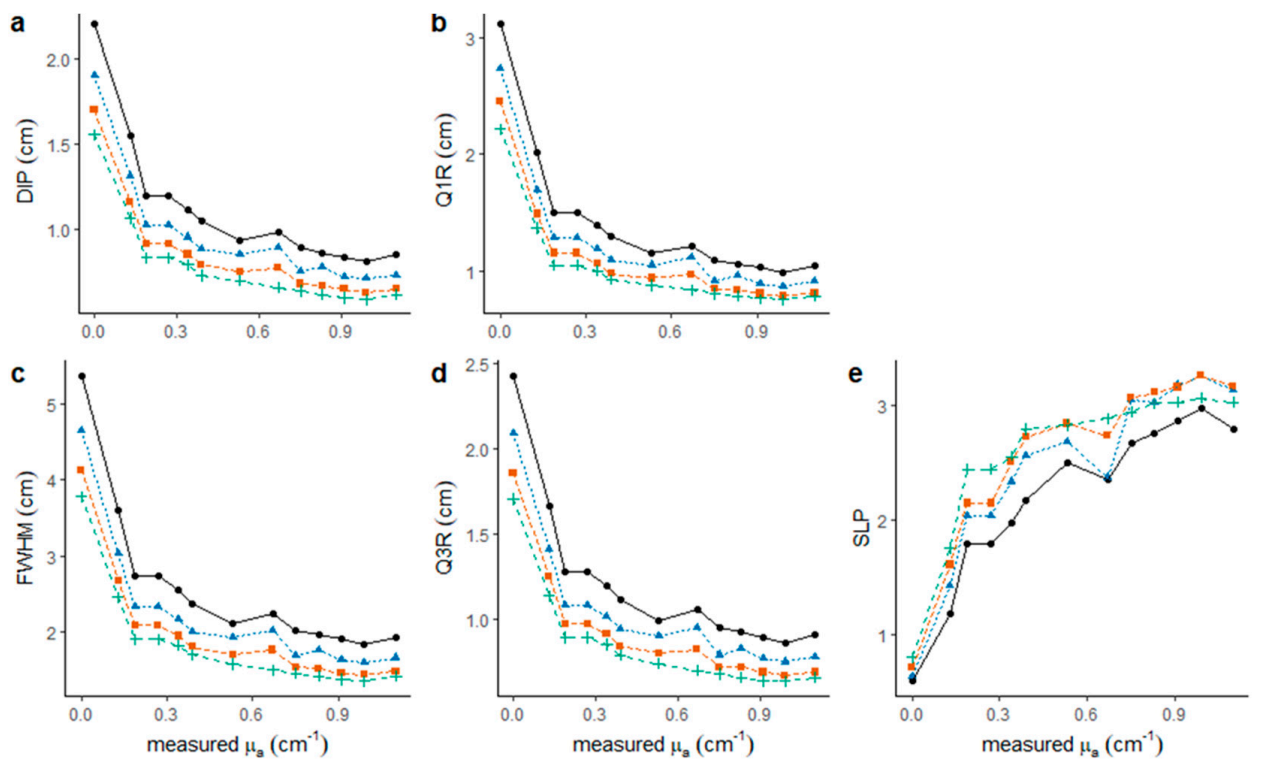

Initial $\mu_{\mathrm{s}}^{\prime}\left(\mathrm{cm}^{-1}\right) \rightarrow 1.86 \cdots 3.10-4.34-+5.59$

Figure 3. Parameters extracted from LBI profiles at $520 \mathrm{~nm}$ after imaging processing considering $4 \mathrm{known} \mu_{\mathrm{s}}{ }^{\prime *}$. LBI parameters were the (a) radius of the saturated area (DIP), (b) the radius at $75 \%$ of maximum intensity (Q1R), (c) double the radius at $50 \%$ of maximum intensity (FWHM), (d) radius at $25 \%$ of maximum intensity (Q3R), and (e) slope of the linear regression model (SLP) built with log-transformed profile data between Q1R and Q3R.
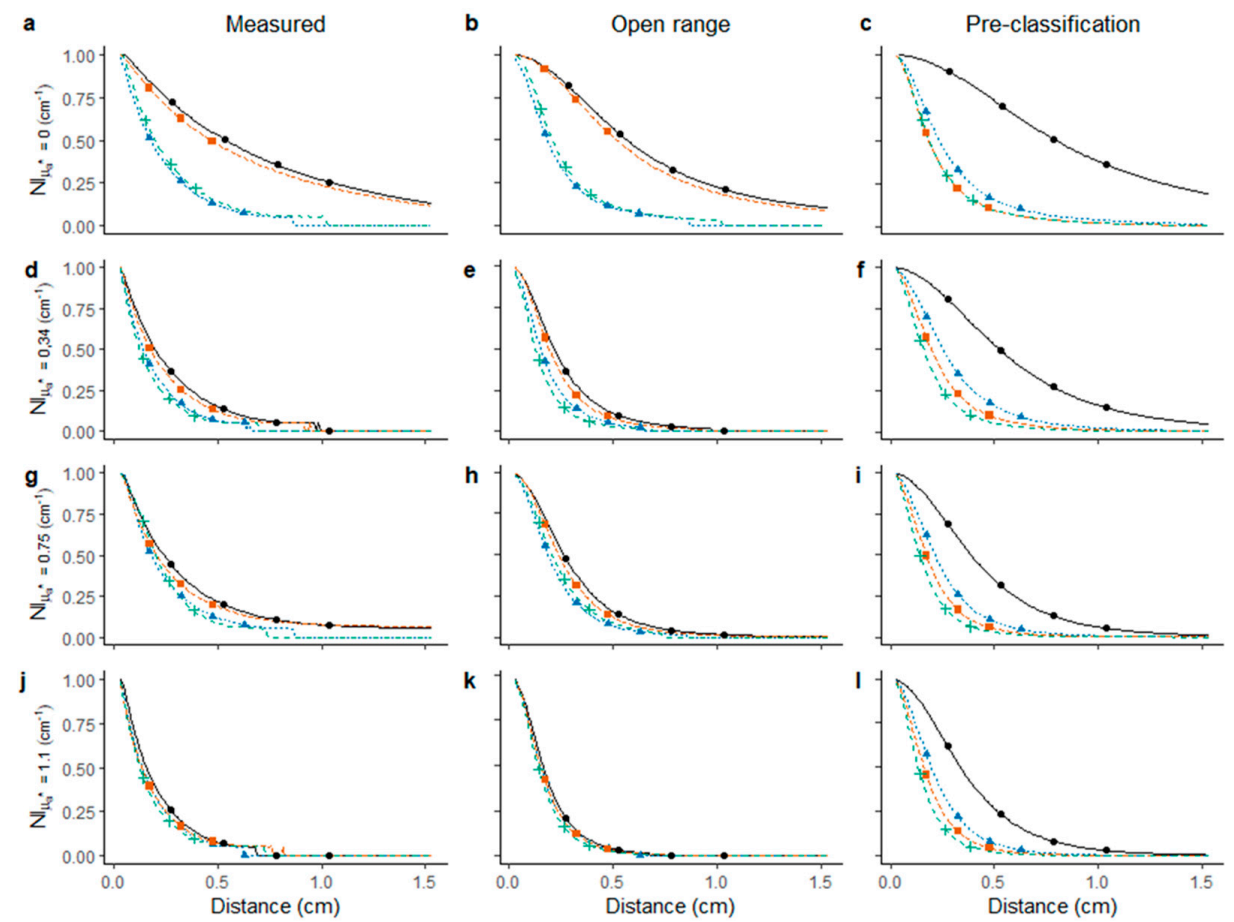

Initial $\mu_{\mathrm{s}}{ }^{\prime}\left(\mathrm{cm}^{-1}\right)$

$\rightarrow 1.86$-.. $3.10-5.34-+-5.59$

Figure 4. Diffusion profile of liquid phantoms obtained by LBI measurement at $520 \mathrm{~nm}(\mathbf{a}, \mathbf{d}, \mathbf{g}, \mathbf{j})$; simulated profiles using Farrell equation with measured $\mu_{\mathrm{a}}{ }^{*}$ and predicted $\mu_{\mathrm{s}}{ }^{\prime}$ of phantoms without pre-classification $(\mathbf{b}, \mathbf{e}, \mathbf{h}, \mathbf{k})$; simulation using Farrell equation with measured $\mu_{\mathrm{a}}{ }^{*}$ and predicted $\mu_{\mathrm{s}}{ }^{\prime}$ of phantoms after pre-classification $(\mathbf{c}, \mathbf{f}, \mathbf{i}, \mathbf{l})$. Dots mark intensity at $75 \%, 50 \%$ and $25 \%$.

When simulating the diffusion profiles based on $\mu_{\mathrm{a}}{ }^{*}$ and predicted $\mu_{\mathrm{s}}{ }^{*}$, obtained by fitting of the measured LBI profile directly with the Farrell equation with one known 
variable, prediction of $\mu_{\mathrm{s}}{ }^{\prime}$ was possible for $\mu_{\mathrm{a}}{ }^{*}<0.7 \mathrm{~cm}^{-1}$. However, an under-estimation of $\mu_{\mathrm{s}}{ }^{\prime}$ occurred. With enhanced $\mu_{\mathrm{a}}{ }^{*}$, the separation of $\mu_{\mathrm{s}}$ ' showed an increased uncertainty (Figure 5a). Predicted $\mu_{\mathrm{a}}$ calculated from predicted $\mu_{\mathrm{s}}{ }^{\prime}$ (Figure $5 \mathrm{~b}$ ) showed an underestimation of $\mu_{\mathrm{a}}$ with increasing $\mu_{\mathrm{s}}{ }^{\prime}$, resulting in diagonal parallel lines shifting towards the top left for the different $\mu_{\mathrm{s}}{ }^{\prime}$ levels at the same $\mu_{\mathrm{a}}{ }^{*}$ level (Figure $5 \mathrm{~b}$ ). A similar observation of underrepresentation of $\mu_{\mathrm{a}}$ and over-representation of $\mu_{\mathrm{s}}{ }^{\prime}$ was reported by Yang et al. using solid phantoms to build the pre-classification model with $\mu_{\mathrm{a}}{ }^{*}$ and $\mu_{\mathrm{s}}{ }^{*}$ ranging between 0.1-1.3 and 2.0-22.8 $\mathrm{cm}^{-1}$, respectively [31]. When using the FDA pre-classification based on LBI parameters, $\mu_{\mathrm{a}}$ and $\mu_{\mathrm{s}}{ }^{\prime}$ were separated non-destructively. Although prediction bias was found, a potential to use LBI parameters to build a pre-classification model aimed at predicting optical properties (Figure 5c) was confirmed in the present study. However, the prediction error observed in Figure $5 \mathrm{c}$ is high. Previous metamodel approaches used hyperspectral imaging system [29] and liquid phantoms with $\mu_{\mathrm{a}}$ at 550-700 nm and 900-950 nm. A large variation was observed, when $\mu_{\mathrm{a}}$ ranged between $[0,0.5] \mathrm{cm}^{-1}$, while $\mu_{\mathrm{s}}{ }^{\prime}$ prediction reached $R^{2}=0.997$ and RMSE $=0.226 \mathrm{~cm}^{-1}$. Such findings were achieved when the $\mu_{\mathrm{s}}{ }^{\prime}$ levels captured a high range between $[3.8,20] \mathrm{cm}^{-1}$ [29]. A clear level of separation of $\mu_{\mathrm{a}}$ and $\mu_{\mathrm{s}}{ }^{\prime}$ was observed for large ranges of liquid phantom sets, in which $\mu_{\mathrm{a}}$ and $\mu_{\mathrm{s}}{ }^{\prime}$ were between $0-14$ and $0-275 \mathrm{~cm}^{-1}$ [34].
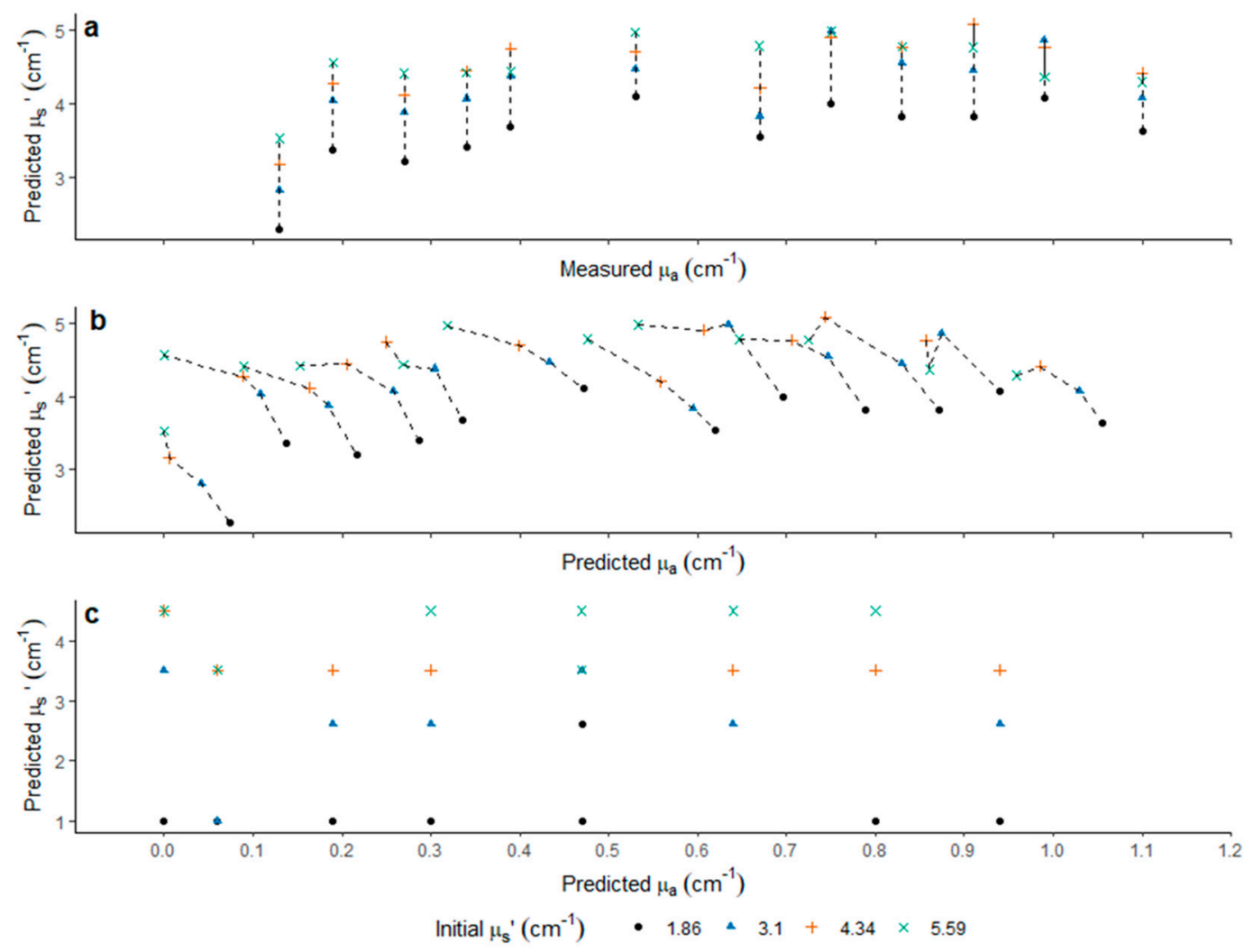

Figure 5. Optical properties prediction of phantom at 4 known $\mu_{\mathrm{s}}{ }^{* *}$ by means of (a) destructively measured $\mu_{\mathrm{a}}{ }^{*}$ and predicted $\mu_{\mathrm{s}}{ }^{\prime}$ directly $\left(\mu_{\mathrm{s}}{ }^{\prime}=\right.$ open range) according to Farrell equation; (b) predicted $\mu_{\mathrm{a}}$ and $\mu_{\mathrm{s}}{ }^{\prime}$ (both open range); (c) predicted $\mu_{\mathrm{a}}$ and $\mu_{\mathrm{s}}{ }^{\prime}$ (both after pre-classification).

At lower absorption levels $\left(\mu_{\mathrm{a}}^{*} \leq 0.59 \mathrm{~cm}^{-1}\right)$, segregation among scattering levels could be observed regardless of the shifting of $\mu_{\mathrm{s}}{ }^{\prime}$ with increasing $\mu_{\mathrm{a}}{ }^{*}$. However, the classification of $\mu_{\mathrm{s}}$ ' is less accurate when $\mu_{\mathrm{a}}{ }^{*}>0.59 \mathrm{~cm}^{-1}$, which might be expected due to the similarity of LBI profiles at higher $\mu_{\mathrm{a}}^{*}$ (Figure 4). Higher accuracy was obtained for predicted $\mu_{\mathrm{a}}$ at lower $\mu_{\mathrm{s}}{ }^{\prime}$. The predicted optical properties (Figure $5 \mathrm{c}$ ) were not separated well. However, pre-classification showed improved prediction for $\mu_{s}$ ', close to the known value $\mu_{\mathrm{s}}{ }^{\prime *}$, with pre-classification (Table 1). Similar results were reported when applying 
time resolved spectroscopy for low $\mu_{\mathrm{s}}{ }^{\prime}$ and high $\mu_{\mathrm{a}}$. When $\mu_{\mathrm{s}}{ }^{\prime}>20 \mathrm{~cm}^{-1}$ and $\mu_{\mathrm{a}}<0.2 \mathrm{~cm}^{-1}$, the model performance was high, and error still less than $20 \%$ when $\mu_{\mathrm{s}}{ }^{\prime}>5 \mathrm{~cm}^{-1}$ [35].

As described previously [22], curve fitting with Farrell equation is reliable when $\mu_{\mathrm{a}}<<\mu_{\mathrm{s}}{ }^{\prime}$, while in the current liquid phantom set, $\mu_{\mathrm{s}}{ }^{\prime}$ was studied within a more narrow range between $[1.86,5.59] \mathrm{cm}^{-1}$ with enhanced resolution compared to earlier research works $[34,35]$. Consequently, limited prediction capacity may have been expected in the range, which is, however, relevant for kiwifruit. The range of optical properties of kiwifruit has been described as $\mu_{\mathrm{a}}$ between $0-0.4 \mathrm{~cm}^{-1}$ and $\mu_{\mathrm{s}}{ }^{\prime}<8 \mathrm{~cm}^{-1}$ within visible-NIR region [36]. Thus, the set of phantoms used in the present study covered the relevant range. The prediction of $\mu_{\mathrm{s}}{ }^{\prime}$ at $\mu_{\mathrm{a}}{ }^{*}=0$ or prediction of $\mu_{\mathrm{s}}{ }^{\prime}$ with an open range without pre-classification, resulted in high difference from actual $\mu_{\mathrm{s}}{ }^{\prime *}$ (Table 1). However, when using the pre-classification, $\mu_{\mathrm{s}}{ }^{\prime}$ was predicted in the correct range.

The pre-classification model was cross-validated with the same set of liquid phantom LBI profiles and the associated $\mu_{\mathrm{a}}{ }^{*}$ and $\mu_{\mathrm{s}}{ }^{*}$. The overall accuracy after pre-classification was $65.6 \%$ and $91.5 \%$ considering $\mu_{\mathrm{a}}$ and $\mu_{\mathrm{s}}{ }^{\prime}$, respectively (Table 2). Classification accuracy of $\mu_{\mathrm{s}}{ }^{\prime}$ (Table 2) was higher than for $\mu_{\mathrm{a}}$, which may be due to the small absorption class intervals used in the classification model as indicated by LBI parameters in Figure 2. The classification accuracy of predicted $\mu_{\mathrm{s}}{ }^{\prime}$ without pre-classification was worse than that using LBI parameters because without limiting the range, predicted $\mu_{\mathrm{s}}$ ' tends to be over-estimated at lower $\mu_{\mathrm{s}}{ }^{\prime}$ levels (Table 1 ). This indicated that $\mu_{\mathrm{s}}{ }^{\prime}$ range is required to be known when using Farrell's equation to get more accurate estimates of $\mu_{\mathrm{s}}{ }^{\prime}$ values.

Table 2. Classification accuracy (\%) for optical properties $\left(\mu_{\mathrm{a}}\right.$ and $\left.\mu_{\mathrm{s}}{ }^{\prime}\right)$ of liquid phantoms using laser backscattering image (LBI) profile parameters with the flexible discriminant analysis (FDA) pre-classification model, Farrell-predicted $\mu_{\mathrm{s}}{ }^{\prime}$ without pre-classification (open-range) and Farrellpredicted $\mu_{\mathrm{s}}{ }^{\prime}$ after pre-classification (pre-classification). Values presented are the average classification accuracy for the $4 \mu_{\mathrm{s}}{ }^{\prime}$ and $8 \mu_{\mathrm{a}}$ ranges.

\begin{tabular}{cccc}
\hline & LBI & Open-Range & Pre-Classification \\
\hline$\mu_{\mathrm{s}}{ }^{\prime}\left(\mathrm{cm}^{-1}\right)$ & 87.5 & 39.3 & 91.5 \\
$\mu_{\mathrm{a}}\left(\mathrm{cm}^{-1}\right)$ & 65.6 & 75.0 & 65.6 \\
\hline
\end{tabular}

\subsection{Kiwifruit Segregation}

\subsubsection{Kiwifruit LBI Profiles}

CI had an effect on flesh firmness and SSC for kiwifruit in severity categories (Table 3). For both cultivars, sound kiwifruit had higher flesh firmness and SSC compared to damaged fruit. This may be explained by advanced ripening due to enhanced ethylene production [6] caused by CI or the disintegration of cell structures and associated tissue damage as a result of CI [37]. Since the number of samples appeared unbalanced, in further analysis subsamples of the entire data sets were used.

Table 3. Kiwifruit average flesh firmness (FF) and soluble solids content (SSC) at different chilling injury (CI) severity. Sound means kiwifruit are free from CI symptoms; moderate means kiwifruit with CI symptoms of granulation but no water soaking; severe means kiwifruit with both CI symptoms of granulation and water soaking.

\begin{tabular}{|c|c|c|c|c|c|c|}
\hline \multirow{2}{*}{$\begin{array}{c}\text { CI } \\
\text { Assessment }\end{array}$} & \multicolumn{3}{|c|}{ SunGold ${ }^{\mathrm{TM}}$} & \multicolumn{3}{|c|}{ Hayward } \\
\hline & $n$ & $F F\left(\mathrm{~kg}_{\mathrm{f}}\right)^{1}$ & SSC (\%) & $n$ & $F F\left(k_{f}\right)$ & SSC (\%) \\
\hline Sound & 320 & $0.88 \mathrm{a}$ & $15.79 a$ & 137 & $1.21 \mathrm{a}$ & $15.25 \mathrm{a}$ \\
\hline Moderate & 64 & $0.76 b$ & $14.22 \mathrm{~b}$ & 179 & $0.97 \mathrm{~b}$ & $15.01 b$ \\
\hline Severe & 12 & $0.74 b$ & $12.23 \mathrm{c}$ & 84 & $0.57 c$ & $14.61 \mathrm{c}$ \\
\hline
\end{tabular}

${ }^{1}$ Different letter for each cultivar and response variable represents a significant difference by Tukey HSD $(p<0.05)$ 
When comparing LBI parameters, Q1R, FWHM and Q3R were reduced in kiwifruit showing severe $\mathrm{CI}$ (Figure 6). This was found regardless of the acquisition position of the LBI on the fruit. The SLP was different among all 3 CI severity classes, suggesting that LBI profiles could be employed to segregate kiwifruit according to the CI severity. Such assumption is supported by the high differences of LBI profiles and corresponding LBI parameters due to changes in optical properties (Figure 4). DIP remained constant for all samples, possibly because DIP describes the saturated area of LBI image, which is mainly affected by the laser power output. Despite the fact that CI symptoms developed from the stylar end, the position of LBI measurement hardly showed any effect on the differences of LBI parameters.
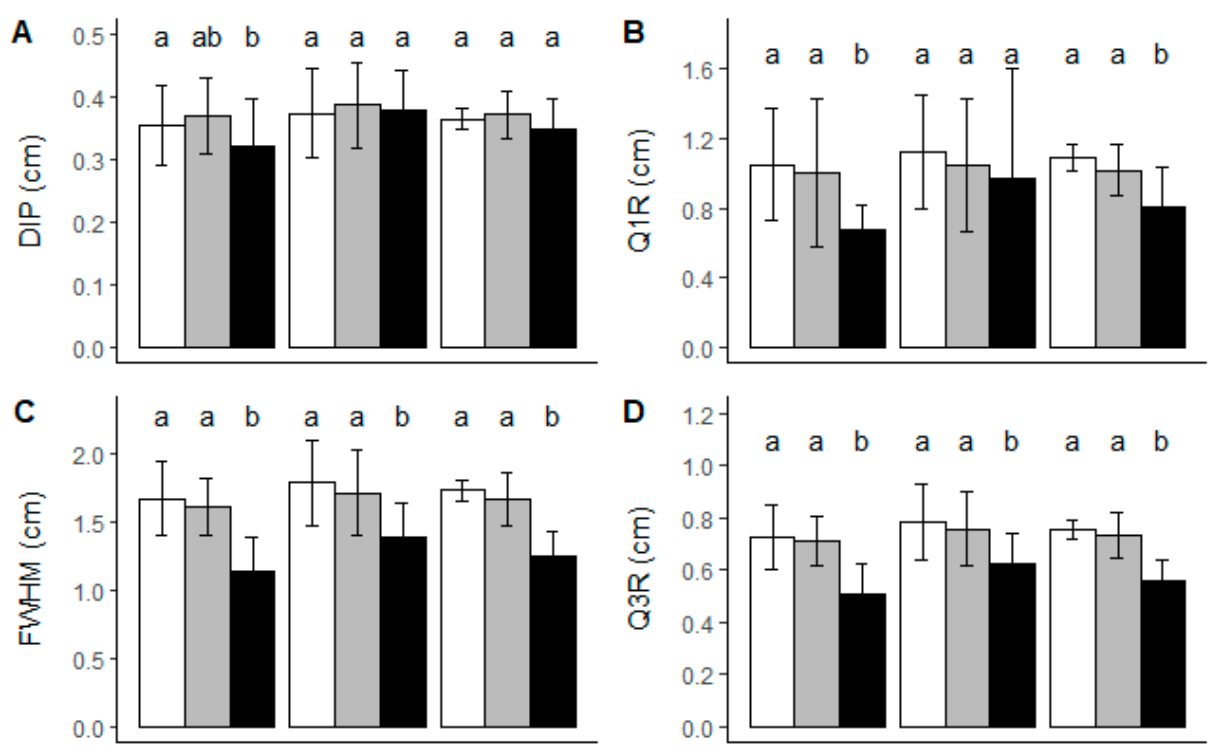

$\mathbf{E}$
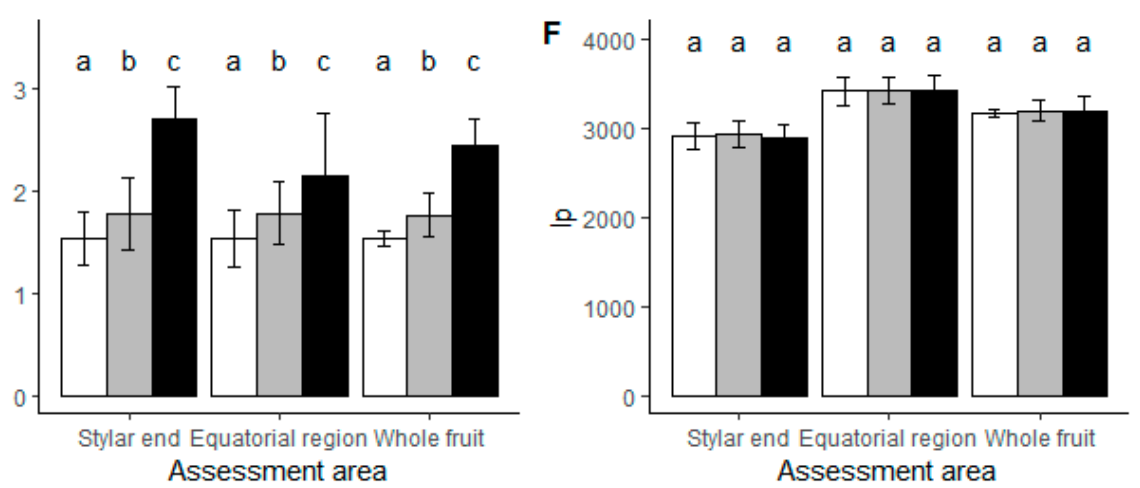

Chilling injury assessment

Sound

Moderate

Severe

Figure 6. 'SunGold ${ }^{\mathrm{TM}}$ ' kiwifruit LBI profile parameters for segregation of chilling injuries (CI) in stored kiwifruit. White, grey and black bars represent $\mathrm{CI}$ assessed as sound (free from CI symptoms), moderate (CI symptoms of granulation but no water soaking) and severe (both CI symptoms of granulation and water soaking) kiwifruit. Lower case letters represent a significant difference between three CI severities by Tukey HSD ( $p$-value $<0.05)$ using LBI taken from two locations or whole fruit. Error bars represent the standard deviation. LBI parameters were (A). the radius of the saturated area (distance to incident point, DIP), (B). the radius at $75 \%$ of maximum intensity (Q1R), (C). double the radius at $50 \%$ of maximum intensity (full width half maximum, FWHM), (D). the radius at 25\% of maximum intensity (Q3R), (E). and the negative slope (SLP) of the linear regression model built with log-transformed profile data between Q1R and Q3R. (F). kiwifruit longitudinal profiles (lp) were compared at positions where LBI taken.

For 'Hayward' kiwifruit, similar results were observed (Figure 7). For LBI images, differences were found in FWHM, Q3R and negative SLP, which may be applied to seg- 
regate kiwifruit based on CI categories. Unlike 'SunGold ${ }^{\mathrm{TM}}$ ', DIP was different for severe CI kiwifruit for 'Hayward' (Figure 7A). Additionally, a longitudinal profile describing the shape difference was observed for different $\mathrm{CI}$ categories at the stylar end (Figure 7F). Shape differences may occur, because the kiwifruit were ungraded and possible correlation between size and CI susceptibility may be a subject to future studies. In general, the least advanced kiwifruit are the smaller size fruit in a batch, which are more susceptible to CI [3].
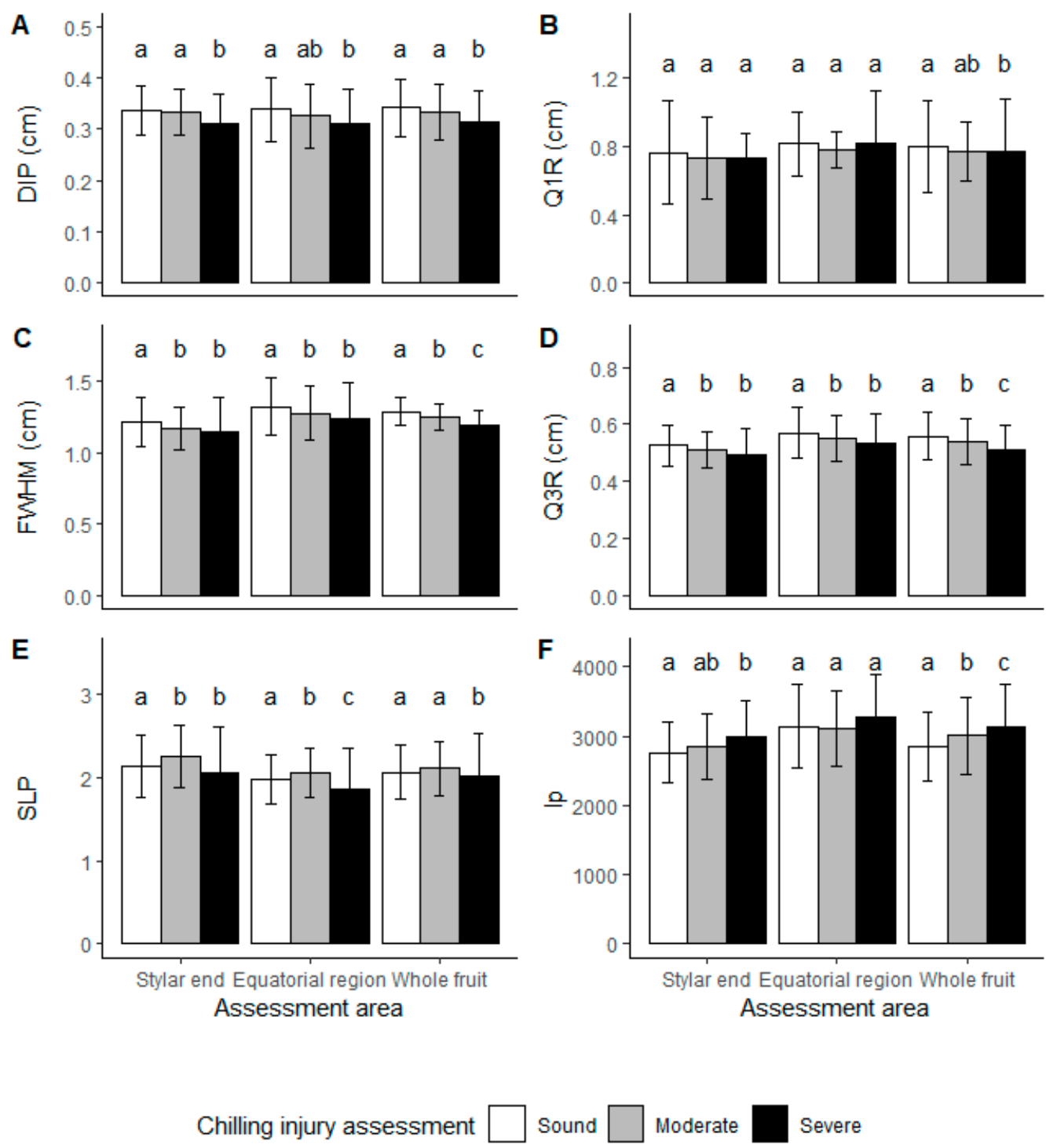

Figure 7. 'Hayward' kiwifruit LBI profile parameters for segregation of chilling injuries (CI) in stored kiwifruit. White, grey and black bars represent CI assessed as sound (free from CI symptoms), moderate (CI symptoms of granulation but no water soaking) and severe (both CI symptoms of granulation and water soaking) kiwifruit. Lower case letters represent a significant difference between three CI severities by Tukey HSD ( $p$-value $<0.05$ ) using LBI taken from two locations or whole fruit. Error bars represent the standard deviation. LBI parameters were (A). the radius of the saturated area (distance to incident point, DIP), (B). the radius at $75 \%$ of maximum intensity (Q1R), (C). double the radius at $50 \%$ of maximum intensity (full width half maximum, FWHM), (D). the radius at $25 \%$ of maximum intensity (Q3R), (E). and the negative slope (SLP) of the linear regression model built with log-transformed profile data between Q1R and Q3R. (F). kiwifruit longitudinal profiles (lp) were compared at positions where LBI taken.

The LBI parameters DIP and SLP differed for severe CI kiwifruit in comparison to the categories of sound and moderate CI fruit. Furthermore, FWHM, Q3R and longitudinal profile were different for all three severities, suggesting a potential to use LBI parameters 
to segregate 'Hayward' kiwifruit with different CI severity. The changes in LBI parameters could result from quality difference (FF and SSC) between CI classes (Table 3). However, granulation and water soaking should be the more dominant effects.

\subsubsection{Kiwifruit LBI Optical Properties}

Optical properties of kiwifruit were predicted employing LBI parameters for preclassification before using Farrell equation for fitting the $\mu_{\mathrm{a}}$ and $\mu_{\mathrm{s}}$ ' to the non-destructively measured LBI diffusion profile. A large standard deviation was observed for predicted $\mu_{\mathrm{a}}$ for both cultivars. Predicted $\mu_{\mathrm{a}}$ was different for sound kiwifruit for 'SunGold ${ }^{\mathrm{TM}}$ ' when measuring at stylar end and equatorial region (Figure 8A), whereas no difference was observed for 'Hayward' (Figure 8B). CI symptoms include pigment changes, such as discolouration of the skin in the outer pericarp region near the stylar end, could be related to $\mu_{\mathrm{a}}$, thus higher $\mu_{\mathrm{a}}$ was observed for kiwifruit with CI. However, for 'Hayward' kiwifruit, CI symptoms did not involve pigment changes on the skin and, consistently, no difference in predicted $\mu_{\mathrm{a}}$ was observed in the 'Hayward' data set. Enhanced predicted $\mu_{\mathrm{s}}$ ' was observed for 'SunGold ${ }^{\mathrm{TM}}$ ' kiwifruit with CI at the stylar end region and 'Hayward' kiwifruit with $\mathrm{CI}$ at the equatorial region (Figure 8C,D). For 'Hayward' kiwifruit, it cannot be confirmed whether the segregation of predicted $\mu_{\mathrm{s}}$ ' was due to granular tissue development around the equator or a difference in flesh firmness, which was also measured around the equator. For the stylar end, it's possible that shape affected LBI results and thus no difference in predicted $\mu_{\mathrm{s}}{ }^{\prime}$ was observed. In the diffusion model described by Farrell et al. [22], the influence of sample curvature is not considered. Qin and Lu calculated a sample size correction factor $\sin \theta$ using spatially resolved diffuse reflectance image and found the corrected $\mu_{\mathrm{s}}{ }^{\prime}$ would be less compared with the predicted value because $\sin \theta<1$ [26]. Therefore, the actual $\mu_{\mathrm{s}}$ ' should be lower than the predicted $\mu_{\mathrm{s}}$ '. Since 'SunGold ${ }^{\mathrm{TM}}$ ' kiwifruit have a more uniform shape and quality parameters, the difference in predicted $\mu_{\mathrm{s}}{ }^{\prime}$ was assumed to be due to the granular or water soaking tissue as these CI symptoms usually develop from the stylar end region [16].

When looking at the kiwifruit optical properties, different $\mu_{\mathrm{s}}{ }^{\prime}$ was observed for both cultivars with moderate and severe CI in comparison to sound kiwifruit (Figure 8C,D). Such findings might be due to enhanced $\mu_{\mathrm{s}}^{\prime}$ caused by the granulated tissue [38]. Different $\mu_{\mathrm{a}}$ was observed between sound and injured kiwifruit for 'SunGold ${ }^{\mathrm{TM}}$ ', and between severe CI and sound-moderate CI for 'Hayward' kiwifruit (Figure 8A,B). Thus, it may be possible to use predicted optical properties to segregate kiwifruit with $\mathrm{CI}$, but the large standard deviation found in phantoms may cause classification errors in kiwifruit. Similar results have been observed in other works. A lower transmitted signal intensity of 'SunGold ${ }^{\mathrm{TM}}$ ' was observed for fruit with CI when using a dual-laser system [29]. Furthermore, a large variation of $\mu_{\mathrm{a}}$ and $\mu_{\mathrm{s}}{ }^{\prime}$ was reported of kiwifruit skin compared with kiwifruit flesh [32]. Kiwifruit flesh tissue had absorption peaks at $970 \mathrm{~nm}, 1190 \mathrm{~nm}$ and $1390 \mathrm{~nm}$ in the NIR region, and the correlation between $\mu_{\mathrm{a}}$ and SSC reached $R^{2}=0.8$ [39]. In the visible region, the peak of green fleshed kiwifruit $\mu_{\mathrm{a}}$ was reported at $675 \mathrm{~nm}$ which is the peak absorption of chlorophyll. The $\mu_{\mathrm{s}}{ }^{\prime}$ prediction in kiwifruit showed lower accuracy within 650-750 nm due to high $\mu_{\mathrm{a}}$ [36,40]. In the present study, high $\mu_{\mathrm{a}}$ was observed at $520 \mathrm{~nm}$ for 'SunGold ${ }^{\mathrm{TM}}$ ' (Figure 8) due to the absorption peak of carotenoids. For 'SunGold ${ }^{\mathrm{TM}}$ kiwifruit optical properties of $\mu_{\mathrm{a}}=0.1 \mathrm{~cm}^{-1}$ and $\mu_{\mathrm{s}}{ }^{\prime}=25 \mathrm{~cm}^{-1}$ were reported [31], because no pigment absorption took place. Unlike $\mu_{\mathrm{a}}$, which had absorption peaks for different chemical compositions, kiwifruit $\mu_{s}{ }^{\prime}$ was steadily decreasing $[36,40]$. Hence, the fruit quality estimation may be more reliable using $\mu_{\mathrm{s}}{ }^{\prime}$. Higher $\mu_{\mathrm{s}}{ }^{\prime}$ and lower $\mu_{\mathrm{a}}$ at $632.8 \mathrm{~nm}$ was observed for kiwifruit flesh (3.8 and $1.17 \mathrm{~cm}^{-1}$ ) compared to kiwifruit seed part (1.2 and $3.08 \mathrm{~cm}^{-1}$ ) due to different microstructure and pigment contents, respectively [41]. Increased $\mu_{\mathrm{s}}{ }^{\prime}$ was observed with decreasing $\mathrm{FF}$, which was explained as new scattering boundaries created when the cell wall was degraded [42]. 

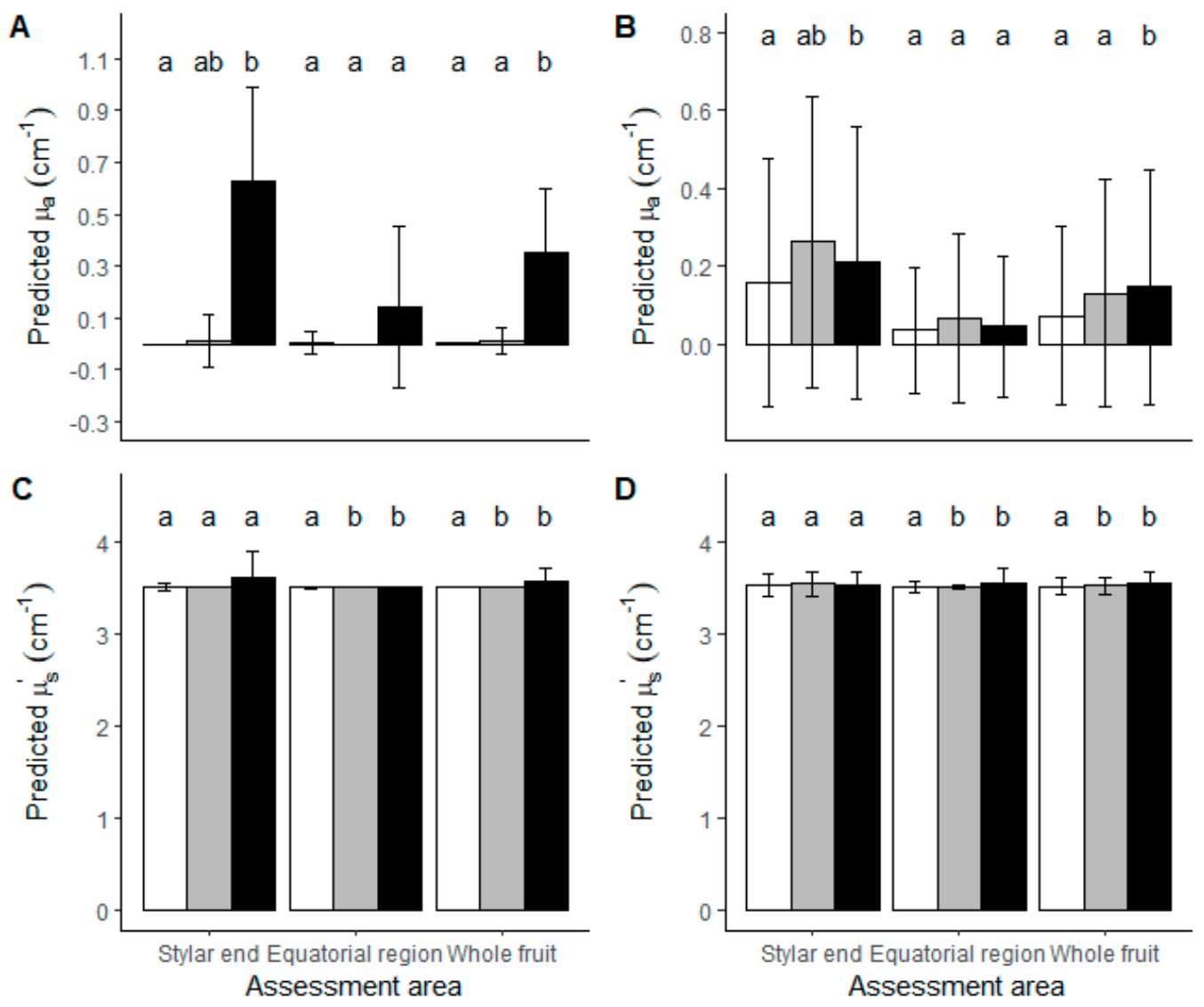

Chilling injury assessment $\square$ sound $\square$ Moderate $\square$ Severe

Figure 8. 'SunGold ${ }^{\mathrm{TM}}$ ' kiwifruit LBI $\mu_{\mathrm{a}}(\mathbf{A})$ and $\mu_{\mathrm{s}}{ }^{\prime}(\mathbf{C})$ and 'Hayward' kiwifruit LBI $\mu_{\mathrm{a}}(\mathbf{B})$ and $\mu_{\mathrm{s}}$ ' (D) for segregation of chilling injuries in stored kiwifruit. White, grey and black bars represent CI assessed as sound (free from CI symptoms), moderate (CI symptoms of granulation but no water soaking) and severe (both CI symptoms of granulation and water soaking) kiwifruit. Lower case letters represent a significant difference between three CI severities by Tukey HSD $(p$-value $=0.05)$ using LBI taken from two locations or whole fruit.

Reasons for this error might be due to the $\mu_{\mathrm{a}}$ and $\mu_{\mathrm{s}}{ }^{\prime}$ range of the liquid phantoms, because many of the kiwifruit were predicted at the highest class after pre-classification. However, this would indicate a larger range of $\mu_{\mathrm{a}}$ than reported in previous work. Furthermore, the ratio of $\mu_{\mathrm{a}}$ and $\mu_{\mathrm{s}}{ }^{\prime}$ in kiwifruit does not meet the assumption $\mu_{\mathrm{a}}<<\mu_{\mathrm{s}}{ }^{\prime}$ [22].

\subsubsection{Segregation of Kiwifruit CI Severity}

For 'SunGold ${ }^{\mathrm{TM}}$ ' kiwifruit, a high classification accuracy of CI was observed for subsampled sound fruit and CI fruit using LBI parameters (Table 4). Higher classification accuracy of CI was obtained using LBI taken at the stylar end region compared to images acquired at the equator, possibly because the kiwifruit stylar end is the likely location for initial CI development [16]. Using whole fruit LBI parameter information acquired from both locations, the classification accuracy of sound and moderate kiwifruit was slightly improved. This finding indicates that the under-sampling error due to CI symptoms not always appearing in the LBI area was reduced by taking an average of images acquired at multiple locations around the fruit. Therefore, taking multiple measurements on the same fruit is recommended for spot-measurement methods such as LBI to capture the damaged tissue. In a sorting line the fruit are usually rolling, and several spots could be analysed. 
Table 4. Classification accuracy (\%) of kiwifruit CI severity using LBI parameters and optical properties after subsampling to avoid unbalanced data set with the same number of kiwifruit in each CI category.

\begin{tabular}{ccccccc}
\hline & \multicolumn{3}{c}{ LBI Parameter } & \multicolumn{3}{c}{$\mu_{\mathrm{a}}$ and $\mu_{\mathbf{s}}{ }^{\prime}$} \\
\hline & Sound & Moderate & Severe & Sound & Moderate & Severe \\
\hline 'SunGold ${ }^{\text {TM' }}(n=36)$ & & & & & & \\
$\quad$ Stylar end & 82 & 71 & 94 & 100 & 0 & 76 \\
Equatorial region & 82 & 53 & 82 & 100 & 0 & 18 \\
Whole fruit & 83 & 75 & 92 & 100 & 0 & 75 \\
\hline 'Hayward' ( $n=252)$ & & & & & & \\
$\quad$ Stylar end & 49 & 47 & 61 & 76 & 43 & 1 \\
Equatorial region & 46 & 42 & 57 & 95 & 8 & 12 \\
Whole fruit & 52 & 36 & 58 & 70 & 21 & 35 \\
\hline
\end{tabular}

Poor classification accuracy was observed for 'Hayward' kiwifruit compared with 'SunGold ${ }^{\mathrm{TM}}$ ' (Table 4). This could be due to 'Hayward' kiwifruit being ungraded thus increasing further variability in having a large variance in size and shape. Furthermore, trichomes could potentially affect the acquisition of diffusion profile.

The advantage of decoupling $\mu_{\mathrm{a}}$ and $\mu_{\mathrm{s}}{ }^{\prime}$ was to separate the information related to chemical composition and cell wall structure. In CI severity detection, $\mu_{\mathrm{s}}{ }^{\prime}$ was expected to be correlated with the presence of granular tissue and water soaking tissue, which are the main symptoms differentiating moderate $\mathrm{CI}$ and sound kiwifruit.

For the two-class segregation application, to segregate severe CI kiwifruit from sound and moderate CI kiwifruit, the use of LBI parameters achieved a true positive and falsenegative rate of $100 \%$ and $8 \%$ for 'SunGold ${ }^{\mathrm{TM}}$ ', and $68 \%$ and $23 \%$ for 'Hayward' considering the same subsampling method (data not shown). However, in real-world situations, CI incidence is low $(<5 \%)$ when appropriate supply chain conditions are applied. 'SunGold ${ }^{\mathrm{TM}^{\prime}}$ had a $92 \%$ and $75 \%$ (Table 5) true positive rate using LBI parameter and $\mu_{\mathrm{a}}$ and $\mu_{\mathrm{s}}$ ' with the whole sample population in this study (sound and moderate CI and severe CI fruit ratio at 32:1 $(n=396)$. In the subsampled population, the data set is small, but confirms the results. For 'Hayward', using the original population (ratio of sound and moderate $\mathrm{CI}$ and severe $\mathrm{CI}$ fruit $=3.65: 1 ; n=400$ ), only a $39 \%$ true positive rate was obtained using LBI parameters and $5 \%$ using $\mu_{\mathrm{a}}$ and $\mu_{\mathrm{s}}{ }^{\prime}$ (Table 5) to predict severe CI in kiwifruit. The good model performance for 'SunGold ${ }^{\mathrm{TM}}$ ' can be explained by the symptoms of skin discolouration and water soaking of severe CI. These changes of kiwifruit influence $\mu_{\mathrm{a}}$ while $\mu_{\mathrm{s}}{ }^{\prime}$ remained unchanged (Figures 6 and $8 \mathrm{~A}, \mathrm{C}$ ). Poor model performance was found for 'Hayward' (Figures 7 and 8B,D).

Table 5. Classification true positive accuracy (\%) of 'SunGold ${ }^{\mathrm{TM}}$ ' and 'Hayward' kiwifruit CI severity using all fruit LBI data without subsampling. $F_{1}$ score is the prediction performance indication for severe CI kiwifruit prediction of the unbalanced dataset using accurately predicted and in-correctly predicted severe CI values.

\begin{tabular}{cccc}
\hline & Sound-Moderate & Severe & F $_{\mathbf{1}}$ Score \\
\hline 'SunGold ${ }^{\mathrm{TM}}$ ' & $n=384$ & $n=12$ & \\
LBI parameters & 98 & 92 & 0.73 \\
$\mu_{\mathrm{a}}$ and $\mu_{\mathrm{s}}$ ' & 99 & 75 & 0.72 \\
\hline 'Hayward' & $n=316$ & $n=84$ & \\
LBI parameters & 97 & 39 & 0.53 \\
$\mu_{\mathrm{a}}$ and $\mu_{\mathrm{s}}$ ' & 100 & 5 & 0.09 \\
\hline
\end{tabular}

\section{Conclusions}

This work demonstrates that LBI techniques provide a potential non-destructive method for the detection of CI in kiwifruit. The severity of CI could be segregated using 
optical properties of the fruit (i.e., $\mu_{\mathrm{a}}$ and $\mu_{\mathrm{s}}{ }^{\prime}$ ). Using a pre-classification model built on liquid phantoms to calibrate the reference matrix of optical properties is a feasible approach to decouple $\mu_{\mathrm{a}}$ and $\mu_{\mathrm{s}}{ }^{\prime}$. The calibration ranges captured the optical properties of kiwifruit providing a reduced effective range compared to earlier successful approaches. The current pre-classification model with the limited effective range has high prediction uncertainties, which may be difficult to overcome. However, for classification questions, the obtained results provide a feasible approach. Future research is required to further improve the pre-classification model, bias correction for fruit curvature, and measurements on several spots on the kiwifruit for application in a sorting line.

Author Contributions: Conceptualization, M.Z.-S., and M.L.; methodology, Z.Y., M.Z.-S., and M.L.; software, Z.Y. and M.Z.-S.; formal analysis, Z.Y.; investigation, Z.Y.; resources, M.Z.-S., M.L. and A.R.E.; data curation, Z.Y.; writing-original draft preparation, Z.Y.; writing-review and editing, M.Z.-S., M.L. and A.R.E.; visualization, Z.Y.; supervision, M.Z.-S., M.L. and A.R.E.; project administration, M.Z.-S., M.L. and A.R.E.; funding acquisition, M.L. and A.R.E. All authors have read and agreed to the published version of the manuscript.

Funding: Zhuo Yang was funded by Zespri International with Zespri Innovation PhD Scholarship.

Acknowledgments: The authors would like to acknowledge Christian Regen from ATB, Ian Thomas, John Pedley and Peter Jeffery from Massey University for supporting the system assembly, Micaela Paz Reyes Potin and Sue Nicholson from Massey for kiwifruit assessment; Steve Glasgow from Massey for assisting liquid phantom preparation; Start AFresh for suppling CI 'Hayward' kiwifruit from a large trial; Zespri Innovation Team and Anthony Pangborn from ARM for organising 'SunGold ${ }^{\mathrm{TM}}$ ' kiwifruit.

Conflicts of Interest: The authors declare no conflict of interest.

\section{References}

1. Parkin, K.L.; Marangoni, A.; Jackman, R.L.; Yada, R.Y.; Stanley, D.W. Chilling Injury. A Review of Possible Mechanisms. J. Food Biochem. 1989, 13, 127-153. [CrossRef]

2. Burdon, J.; Lallu, N. Kiwifruit (Actinidia spp.). In Postharvest Biology and Technology of Tropical and Subtropical Fruits; Elsevier: Amsterdam, The Netherlands, 2011; pp. 326-362. ISBN 978-1-84569-735-8.

3. Burdon, J.; Wohlers, M.; Pidakala, P.; Laurie, T.; Punter, M.; Billing, D. The Potential for Commonly Measured At-Harvest Fruit Characteristics to Predict Chilling Susceptibility of 'Hort16A' Kiwifruit. Postharvest Biol. Technol. 2014, 94, 41-48. [CrossRef]

4. Zhao, J.M.; Bronlund, J.E.; East, A.R. Effect of Cooling Rate on Kiwifruit Firmness and Rot Incidence in Subsequent Storage. Acta Hortic. 2015, 1079, 313-318. [CrossRef]

5. Gwanpua, S.G.; Jabbar, A.; Zhao, M.; Heyes, J.A.; East, A.R. Investigating the Potential of Dual Temperature Storage as a Postharvest Management Practice to Mitigate Chilling Injury in Kiwifruit. Int. J. Refrig. 2018, 86, 62-72. [CrossRef]

6. Jabbar, A.; East, A.R. Quantifying the Ethylene Induced Softening and Low Temperature Breakdown of 'Hayward' Kiwifruit in Storage. Postharvest Biol. Technol. 2016, 113, 87-94. [CrossRef]

7. Kader, A.A. Postharvest Technology of Horticultural Crops, 3rd ed.; University of California Agriculture and Natural Resources: Davis, CA, USA, 2002; Volume 3311.

8. Wang, C.Y. Chilling Injury of Tropical Horticultural Commodities. HortScience 1994, 29, 986-988. [CrossRef]

9. Haishi, T.; Koizumi, H.; Arai, T.; Koizumi, M.; Kano, H. Rapid Detection of Infestation of Apple Fruits by the Peach Fruit Moth, Carposina Sasakii Matsumura, Larvae Using a 0.2-T Dedicated Magnetic Resonance Imaging Apparatus. Appl. Magn. Reson. 2011, 41, 1-18. [CrossRef] [PubMed]

10. McCarthy, M.J.; Zion, B.; Chen, P.; Ablett, S.; Darke, A.H.; Lillford, P.J. Diamagnetic Susceptibility Changes in Apple Tissue after Bruising. J. Sci. Food Agric. 1995, 67, 13-20. [CrossRef]

11. Barreiro, P.; Moya, A.; Correa, E.; Ruiz-Altisent, M.; Fernández-Valle, M.; Peirs, A.; Wright, K.M.; Hills, B.P. Prospects for the Rapid Detection of Mealiness in Apples by Nondestructive NMR Relaxometry. Appl. Magn. Reson. 2002, 22, 387-400. [CrossRef]

12. Shahin, M.A.; Tollner, E.W.; McClendon, R.W.; Arabnia, H.R. Apple Classification Based on Surface Bruises Using Image Processing and Neural Networks. Trans. Am. Soc. Agric. Eng. 2002, 45, 1619-1627.

13. Kim, S.; Schatzki, T.F. Apple Watercore Sorting System Using X-Ray Imagery: I. Algorithm Development. Trans. Am. Soc. Agric. Eng. 2000, 43, 1695-1702. [CrossRef]

14. Varith, J.; Hyde, G.M.; Baritelle, A.L.; Fellman, J.K.; Sattabongkot, T. Non-Contact Bruise Detection in Apples by Thermal Imaging. Innov. Food Sci. Emerg. Technol. 2003, 4, 211-218. [CrossRef]

15. Walsh, K.B.; Blasco, J.; Zude-Sasse, M.; Sun, X. Visible-NIR 'Point' Spectroscopy in Postharvest Fruit and Vegetable Assessment: The Science behind Three Decades of Commercial Use. Postharvest Biol. Technol. 2020, 168, 111246. [CrossRef] 
16. Wang, Z.; Künnemeyer, R.; McGlone, A.; Burdon, J. Potential of Vis-NIR Spectroscopy for Detection of Chilling Injury in Kiwifruit. Postharvest Biol. Technol. 2020, 164, 111160. [CrossRef]

17. Kemsley, E.K.; Tapp, H.S.; Binns, R.; Mackin, R.O.; Peyton, A.J. Feasibility Study of NIR Diffuse Optical Tomography on Agricultural Produce. Postharvest Biol. Technol. 2008, 48, 223-230. [CrossRef]

18. Lu, R.; Van Beers, R.; Saeys, W.; Li, C.; Cen, H. Measurement of Optical Properties of Fruits and Vegetables: A Review. Postharvest Biol. Technol. 2020, 159, 111003. [CrossRef]

19. Cen, H.; Lu, R.; Zhu, Q.; Mendoza, F. Nondestructive Detection of Chilling Injury in Cucumber Fruit Using Hyperspectral Imaging with Feature Selection and Supervised Classification. Postharvest Biol. Technol. 2016, 111, 352-361. [CrossRef]

20. ElMasry, G.; Wang, N.; Vigneault, C. Detecting Chilling Injury in Red Delicious Apple Using Hyperspectral Imaging and Neural Networks. Postharvest Biol. Technol. 2009, 52, 1-8. [CrossRef]

21. Li, M.; Pullanagari, R.R.; Pranamornkith, T.; Yule, I.J.; East, A.R. Quantitative Prediction of Post Storage ‘Hayward' Kiwifruit Attributes Using at Harvest Vis-NIR Spectroscopy. J. Food Eng. 2017, 202, 46-55. [CrossRef]

22. Farrell, T.J.; Patterson, M.S.; Wilson, B. A Diffusion Theory Model of Spatially Resolved, Steady-State Diffuse Reflectance for the Noninvasive Determination of Tissue Optical Properties in Vivo. Med. Phys. 1992, 19, 879-888. [CrossRef]

23. Hashim, N.; Pflanz, M.; Regen, C.; Janius, R.B.; Abdul Rahman, R.; Osman, A.; Shitan, M.; Zude, M. An Approach for Monitoring the Chilling Injury Appearance in Bananas by Means of Backscattering Imaging. J. Food Eng. 2013, 116, 28-36. [CrossRef]

24. Lu, R.; Peng, Y. Assessing Peach Firmness by Multi-Spectral Scattering. J. Near Infrared Spectrosc. 2005, 13, 27-35. [CrossRef]

25. Van Beers, R.; Aernouts, B.; León Gutiérrez, L.; Erkinbaev, C.; Rutten, K.; Schenk, A.; Nicolaï, B.; Saeys, W. Optimal IlluminationDetection Distance and Detector Size for Predicting Braeburn Apple Maturity from Vis/NIR Laser Reflectance Measurements. Food Bioprocess Technol. 2015, 8, 2123-2136. [CrossRef]

26. Peng, Y.; Lu, R. Improving Apple Fruit Firmness Predictions by Effective Correction of Multispectral Scattering Images. Postharvest Biol. Technol. 2006, 41, 266-274. [CrossRef]

27. Baranyai, L.; Zude, M. Analysis of Laser Light Migration in Apple Tissue by Monte Carlo Simulation. Prog. Agric. Eng. Sci. 2008, 4, 45-59. [CrossRef]

28. Zude-Sasse, M.; Hashim, N.; Hass, R.; Polley, N.; Regen, C. Validation Study for Measuring Absorption and Reduced Scattering Coefficients by Means of Laser-Induced Backscattering Imaging. Postharvest Biol. Technol. 2019, 153, 161-168. [CrossRef]

29. Aernouts, B.; Erkinbaev, C.; Watté, R.; Van Beers, R.; Do Trong, N.N.; Nicolai, B.; Saeys, W. Estimation of Bulk Optical Properties of Turbid Media from Hyperspectral Scatter Imaging Measurements: Metamodeling Approach. Opt. Express 2015, $23,26049$. [CrossRef] [PubMed]

30. Watté, R.; Aernouts, B.; Beers, R.V.; Saeys, W. Robust Metamodel-Based Inverse Estimation of Bulk Optical Properties of Turbid Media from Spatially Resolved Diffuse Reflectance Measurements. Opt. Express 2015, 23, 27880-27898. [CrossRef]

31. Yang, Z.; Baranyai, L.; Li, M.; East, A.; Regen, C.; Zude-Sasse, M. Absorption and Reduced Scattering Coefficients of Kiwifruit. Presented at the International Symposium on Precision Management of Orchards and Vineyards, Palermo, Italy, 7-11 October 2019.

32. Olatunji, J.R.; Love, R.J.; Shim, Y.M.; East, A.R. A Shape Equation for Hayward Kiwifruit. Int. J. Food Prop. 2019, 22, 371-382. [CrossRef]

33. Adebayo, S.E.; Hashim, N.; Hass, R.; Reich, O.; Regen, C.; Münzberg, M.; Abdan, K.; Hanafi, M.; Zude-Sasse, M. Using Absorption and Reduced Scattering Coefficients for Non-Destructive Analyses of Fruit Flesh Firmness and Soluble Solids Content in Pear (Pyrus Communis 'Conference')_An Update When Using Diffusion Theory. Postharvest Biol. Technol. 2017, 130, 56-63. [CrossRef]

34. Aernouts, B.; Zamora-Rojas, E.; Beers, R.V.; Watté, R.; Wang, L.; Tsuta, M.; Lammertyn, J.; Saeys, W. Supercontinuum Laser Based Optical Characterization of Intralipid ${ }^{\circledR}$ Phantoms in the 500-2250 Nm Range. Opt. Express 2013, 21, 32450-32467. [CrossRef]

35. Cubeddu, R.; Musolino, M.; Pifferi, A.; Taroni, P.; Valentini, G. Time-Resolved Reflectance: A Systematic Study for Application to the Optical Characterization of Tissues. IEEE J. Quantum Electron. 1994, 30, 2421-2430. [CrossRef]

36. Qin, J.; Lu, R. Measurement of the Optical Properties of Fruits and Vegetables Using Spatially Resolved Hyperspectral Diffuse Reflectance Imaging Technique. Postharvest Biol. Technol. 2008, 49, 355-365. [CrossRef]

37. Bauchot, A.D.; Hallett, I.C.; Redgwell, R.J.; Lallu, N. Cell Wall Properties of Kiwifruit Affected by Low Temperature Breakdown. Postharvest Biol. Technol. 1999, 16, 245-255. [CrossRef]

38. Wang, Z.; Künnemeyer, R.; McGlone, A.; Sun, J.; Burdon, J. Comparison of a Dual-Laser and a Vis-NIR Spectroscopy System for Detection of Chilling Injury in Kiwifruit. Postharvest Biol. Technol. 2021, 175, 111418. [CrossRef]

39. Liu, D.; Guo, W.; Li, Q.; Xie, D. Effect of a Plant Growth Regulator on Optical Properties of Kiwifruit during Growth in Wavelength Range of 950-1650 Nm. Postharvest Biol. Technol. 2019, 156, 110918. [CrossRef]

40. Cubeddu, R.; D’Andrea, C.; Pifferi, A.; Taroni, P.; Torricelli, A.; Valentini, G.; Dover, C.; Johnson, D.; Ruiz-Altisent, M.; Valero, C. Nondestructive Quantification of Chemical and Physical Properties of Fruits by Time-Resolved Reflectance Spectroscopy in the Wavelength Range 650-1000 Nm. Appl. Opt. 2001, 40, 538-543. [CrossRef]

41. Fang, Z.; Fu, X.; He, X. Investigation of Absorption and Scattering Characteristics of Kiwifruit Tissue Using a Single Integrating Sphere System. J. Zhejiang Univ. Sci. B 2016, 17, 484-492. [CrossRef] [PubMed]

42. Tu, K.; Baerdemaeker, J.D.; Deltour, R.; Barsy, T.D. Monitoring Post-Harvest Quality of Granny Smith Apple under Simulated Shelf-Life Conditions: Destructive, Non-Destructive and Analytical Measurements. Int. J. Food Sci. Technol. 1996, 31, 267-276. [CrossRef] 